\title{
Design of a 1-MV induction cavity and validation of the two-dimensional circuit model
}

\author{
Fan Guo, ${ }^{1,2, *}$ Weiping Xie, ${ }^{1}$ Zhi Wang, ${ }^{1}$ Jihao Jiang, ${ }^{1}$ Minghe Xia, ${ }^{1}$ Bing Wei, ${ }^{1}$ Shuping Feng, ${ }^{1}$ \\ Yue Zhao, ${ }^{1}$ Junjun Kang, ${ }^{1}$ Meng Wang, ${ }^{1}$ Wenkang Zou, ${ }^{1}$ and Lin Chen ${ }^{1}$ \\ ${ }^{1}$ Institute of Fluid Physics, China Academy of Engineering Physics, Mianyang 621900, China \\ ${ }^{2}$ University of Science and Technology of China, Hefei 230026, China
}

(Received 3 July 2018; published 4 February 2019)

\begin{abstract}
We present the design and test results of an induction cavity, which is a full-scale prototype cell of a prospective six-stage induction voltage adder. This induction cell runs in positive polarity and the output transmission line operates in the vacuum insulation state. The design methods and configurations of the azimuthal transmission line, insulation stack, magnetic core, cathode plate, and output transmission line in the induction cell are given in detail. The induction cavity is driven by one pulsed power system consisting of a tesla transformer, intermediate storage capacitor, laser triggered gas switch, pulse forming line, selfbreaking oil switch, and a water transmission line. A maximum voltage about $1.05 \mathrm{MV}$ could be achieved across one $7.0 \Omega$ water resistor load. A full circuit model including the primary energy storage section and pulse forming section is proposed. The circuit model also includes the two-dimensional circuit model of the induction cavity [Phys. Rev. Accel. Beams 20, 020401 (2017)]. The voltage and current waveforms across the feed port, azimuthal transmission line, insulation stack, and resistor load obtained during the experiment are compared with the circuit simulation results. It demonstrates that they can agree with each other very well.
\end{abstract}

DOI: 10.1103/PhysRevAccelBeams.22.020401

\section{INTRODUCTION}

The induction voltage adder (IVA) has been widely used for many applications, such as flash radiography [1,2], detection of fissile material [3], gamma-ray simulation [4], and also serves as the injector for the linear induction accelerator [5]. At present, many IVAs are being conducted or built around the world such as Hermes III [6], Radiographic Integrated Test Stand (RITS) [7-9], Cygnus [10] in the United States, Merlin [11] in Atomic Weapons Establishment (AWE) in the United Kingdom, and Jianguang accelerator [12] in Northeast Institute of Nuclear Technology (NINT) in China for various research aims.

IVA is a method of connecting driving circuits in series by induction cavities to achieve a much higher voltage output. The driving section of each induction cavity operates at a relatively low voltage, and their summed voltages are restricted to a small region which is usually termed as output transmission line. This is very helpful to increase flexibility and advance reliability of the machine.

\section{*394560789@qq.com}

Published by the American Physical Society under the terms of the Creative Commons Attribution 4.0 International license. Further distribution of this work must maintain attribution to the author(s) and the published article's title, journal citation, and DOI.
Another advantage of the IVA is that the large-scale insulation stack at the load region could be avoided. It is beneficial to decrease the load current rise time [13,14]. The above-mentioned advantages have prompted the instigation of an IVA research program to investigate the flash radiography in our laboratory. This machine would produce a peak load voltage of $4.0 \mathrm{MV}$ into an approximate $40.0 \Omega$ rod-pinch diode (RPD). The expected x-ray dose at $1.0 \mathrm{~m}$ and source diameter are about $10.0 \mathrm{rad}$ and $1.5 \mathrm{~mm}$, respectively. This prospective IVA is composed of six stages. Each stage is identical and composed of a tesla transformer, intermediate storage capacitor, laser triggered gas switch (LTGS), pulse forming line (PFL), self-breaking oil switch, water transmission line, and one induction cavity. The tesla transformer is employed to provide the primary energy, and each pulse forming section produces a forward-going voltage wave with maximum value about $800 \mathrm{kV}$ and full-width-at-half-maximum (FWHM) about $60.0 \mathrm{~ns}$ that drives the corresponding induction cell. The voltage pulses are added along the output transmission line of the induction cells. In order to get the required small spot size x-ray source, the output transmission line is in positive polarity and operates as a lossless vacuum insulated transmission line.

In this paper, we describe a full-scale prototype induction cell of the prospective 4.0 MV generator. A $7.0 \Omega$ water resistor load is connected to the induction cavity, and the inductance of this load is about $190 \mathrm{nH}$. For a typical shot, a 
maximum voltage about $1.05 \mathrm{MV}$ could be obtained on this load, and the peak value of the load current is $108.0 \mathrm{kA}$. The design methods of the azimuthal transmission line, insulation stack, magnetic core, and output transmission line of the induction cavity will be validated, and the twodimensional (2D) circuit model of the induction cell proposed previously will be confirmed by the experiment results [15]. The exactness of this circuit model is very crucial to estimate the voltage pulse delivered to the RPD and determine the IVA configuration necessary to generate the desired voltage pulse. The experience gained from this program is also valuable to build the future IVA. The advantage of our induction cavity is the use of 2605SA1 amorphous alloy as opposed to the more expensive 2605Co material found in similar IVAs such as RITS, Cygnus, and Merlin. Another specific feature is that one constant impedance azimuthal transmission line is employed, which is also different from the azimuthal transmission lines configurations in the RITS and Merlin machines.

The paper is organized as follows: in the next section, we will give a general description of each element in the induction cell. The detailed design criteria and configurations of each element are also shown in Sec. II. In Sec. III, we will describe the experiment results. The induction cell 2D circuit model will be checked with the experiment results, and the corresponding results will also be shown in Sec. III. Section IV presents conclusions.

\section{DESIGN OF THE INDUCTION CAVITY}

Figure 1 shows the cross section view of an induction cavity. It has only one feed port and operates in positive polarity. The pulsed power generated by the pulse forming section transmits across the feed port into the cell and then flows along two opposite directions through the azimuthal transmission line. The azimuthal transmission line is composed of a curved high voltage electrode and induction cavity shell. The cathode plate is electrically connected with the azimuthal transmission line at certain parts of the entire circumference via connecting tabs. The insulation stack serves as a barrier between the oil and vacuum regions. The regions outside the insulation stack are full of transformer oil, while the inward regions are in vacuum. The magnetic cores are employed to reduce the current flowing from the cathode plate to induction cavity shell which is termed as loss current. As the insulation stack must operate at relatively low electric fields and have a large high voltage-to-ground spacing, the cathode plate is employed to reduce the cell inductance and help grade the voltage uniformly along the insulation stack. The high voltage pulses generated by the pulse forming sections are added at the output transmission line region, and the voltage at this region rises stage by stage.

According to the iterated circuit simulation, the maximum voltage in the induction cavity should be about 1.3 MV in order to obtain a 1.0 MV voltage pulse on

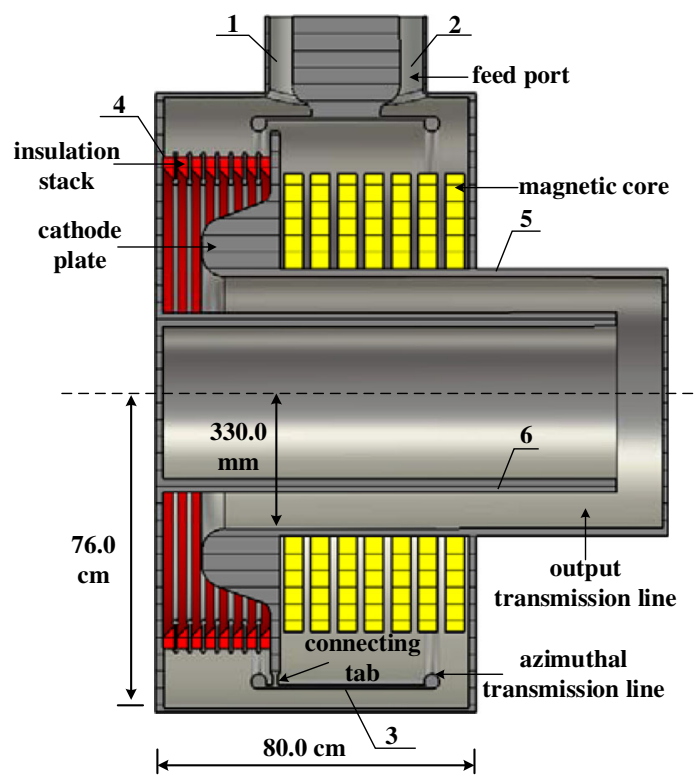

FIG. 1. View of an induction cavity which mainly includes feed port, azimuthal transmission line, connecting tab, insulation stack, magnetic core, cathode plate, and output transmission line. 1 and 2 denote the locations of the D-dot and B-dot monitors which are fielded during our experiment to measure the voltage and current at the feed port, respectively. 3 indicates the positions of the D-dot sensors for azimuthal transmission line voltages measurement, and there are two probes placed at 90 and 180 degrees. The angles are measured in each direction from the midpoint of the feed port. 4 depicts the locations of the two D-dot probes for insulation stack voltages detection at 30 and 90 degrees. 5 represents the locations of the D-dot and B-dot probes for load voltage and current measurement on the output transmission line cathode conductor. At this cross section, two B-dot sensors were employed to detect the load current, and two D-dot probes were used to diagnose the load voltage. They were placed azimuthally. 6 indicates the positions of the D-dot and B-dot monitors on the anode electrode as those on the cathode conductor. There were totally four D-dot monitors measuring the load voltage and also four B-dot sensors diagnosing the load current. The radius and axial lengths of our induction cell were about 760.0 and $800.0 \mathrm{~mm}$, respectively.

the water resistor load (the circuit simulation results will be shown in the next section and compared with the experiment results). In order to get a conservative design, the peak voltages at the azimuthal transmission line, insulation stack, magnetic core, and cathode plate were considered to be $1.3 \mathrm{MV}$ when calculating the electric stresses on each element.

\section{A. Azimuthal transmission line}

The azimuthal transmission line is employed to obtain symmetric magnetic field distribution in the output transmission line region, as the azimuthal magnetic field asymmetry not only perturbs the electron flow in the magnetically insulated transmission line (MITL) but also 
increases the induction cell equivalent inductance [16,17]. The first designing objective is to make the azimuthal magnetic field as uniform as possible at the output transmission line section by adjusting the configuration of the connecting tabs and impedance profile of the azimuthal transmission line. However, the relationship between the magnetic field asymmetry and the loss current in MITL is still unclear. Previous experiments conducted on the RITS machine indicated that the loss current was not significantly increased with the azimuthal magnetic field uniformity significantly worse than the best design. In fact, losses of order $10 \%$ were recorded even though the azimuthal transmission line was removed [18].

As the power flow propagation along the azimuthal transmission line has two parallel paths extending away from the feed port, the actual characteristic impedance of the azimuthal transmission line in both directions should be halved. Previous investigations suggested that the voltage across the induction cell feed port was strongly influenced by the actual azimuthal transmission line impedance, and the ideal value of the impedance was equal to that of the water transmission line which drove the induction cavity [15]. Since the width of the azimuthal transmission line high voltage electrode is narrower than the length of the induction cell, the azimuthal transmission line is treated as a microstrip transmission line. Its actual impedance is estimated by [19]

$Z=\frac{377}{2 \sqrt{\varepsilon_{r}}} \frac{1}{w / d+1.393+0.667 \ln (w / d+1.444)}$,

where $\varepsilon_{r}$ is the relative permittivity of insulation medium which is always the transformer oil, $w$ refers to the width of the azimuthal transmission line high voltage electrode, and $d$ is the radial distance between the high voltage electrode and the inner cylindrical surface of the induction cell.

The transformer oil insulation is another concern that should be taken into consideration. It determines the radial distance between the azimuthal transmission line high voltage electrode and the induction cavity inner cylindrical shell. The empirical formula proposed by Martin is usually employed to estimate the breakdown field in the transformer oil [20,21]:

$E_{+}=0.48 t_{\mathrm{eff}}^{-1 / 3} A^{-0.075}$,

$E_{-}=0.667 t_{\mathrm{eff}}^{-1 / 3} A^{-0.075}\left[1+0.12\left(E_{\mathrm{max}} / E_{\mathrm{mean}}-1\right)^{0.5}\right]$,

where $E_{+}$and $E_{-}$refer to the stresses at which positive and negative electrodes have a $50 \%$ probability of breakdown, respectively, in $\mathrm{MV} / \mathrm{cm}, t_{\mathrm{eff}}$ is the effective pulse duration defined as the time during which the voltage is above $63 \%$ of the peak value in $\mu s, A$ indicates the stressed area where the electric field is above $90 \%$ of the maximum field in $\mathrm{cm}^{2}$, and $E_{\max }$ and $E_{\text {mean }}$ are the peak and mean electric fields for the stressed area, respectively, also in $\mathrm{MV} / \mathrm{cm}$.

The voltage distribution along the insulator rings and the axial electric fields grading outside the magnetic cores are also related to the azimuthal transmission line configuration. They codetermine the width of the azimuthal transmission line high voltage electrode. The voltages across the insulator rings close to the cathode plate are usually less than the average level if they are surrounded by the azimuthal transmission line high voltage electrode [22]. Therefore, the high voltage conductor at this side should not wrap around too many pieces of insulator rings. Another side is restricted by the axial electric fields grading external to the magnetic cores. In order to make the electric fields distribution in this area as uniform as possible, the high voltage electrode's edge should approach the central magnetic core [18].

There are three types of azimuthal transmission lines for the single feed port induction cell as displayed in Fig. 2. The first one has a constant width in high voltage electrode and a constant impedance profile along the whole circumference [12]. The second category is a tapered width in high voltage conductor. It has maximum width on the side of the cavity where the pulse is injected into the cell. As the electrical power flows around the azimuthal direction, the high voltage conductor width decreases and wave impedance increases to compensate for the current flowing in the radial direction around the cathode plate [7]. The last one has an azimuthal transmission line network which is composed of two discrete transmission lines [11].

The detailed advantages and drawbacks for each category are analyzed via transient electromagnetic and electrostatic simulations [23]. For the azimuthal transmission line with constant impedance profile, the symmetry of the azimuthal magnetic field in the output transmission line was the worst among the three choices. The simulation results also suggested that uniform axial electric fields grading outside the magnetic cores and balanced voltage distribution along the insulator rings were hard to obtain. However, a slightly higher load voltage could be achieved with this type of azimuthal transmission line, and the electric stresses across the induction cell feed port and azimuthal transmission line sections were relatively low. It was also relatively easy to be manufactured when discussing with a mechanical engineer.

As the output transmission line in our induction cavity operates as a vacuum insulated transmission line and electron emission from the cathode electrode is neglectable, the symmetry of the azimuthal magnetic field is not desirable. The constant impedance azimuthal transmission line was employed. The radial distance between the azimuthal transmission line high voltage electrode and the induction cavity inner cylindrical shell was $5.0 \mathrm{~cm}$, and the width of the high voltage conductor was $450.0 \mathrm{~mm}$. Hence, the actual characteristic impedance of the azimuthal 

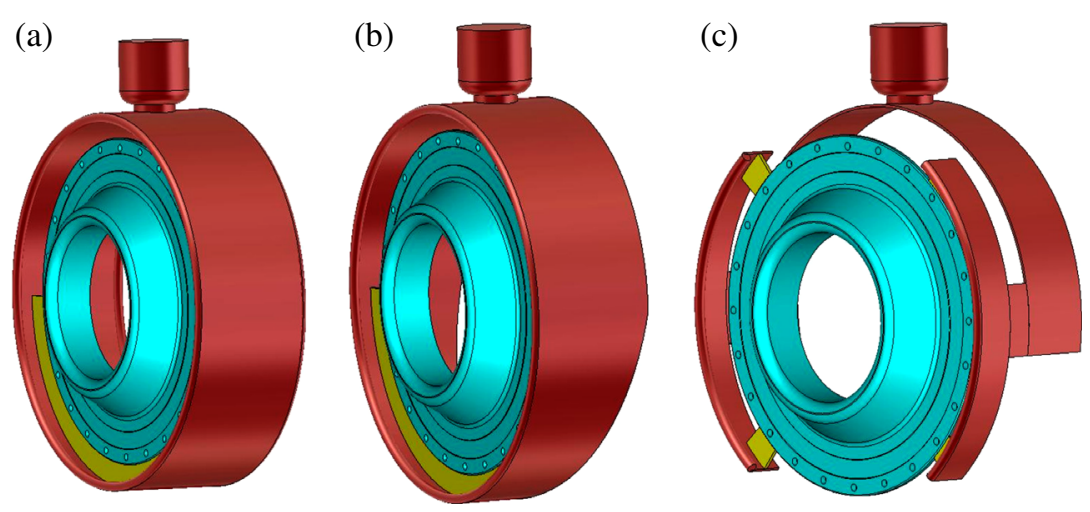

FIG. 2. Schematic of three kinds of azimuthal transmission line high voltage conductors and connecting tabs. (a) The width of high voltage electrode is constant along the power flow direction, and one continuous tab on the lower half circle allows conduction from the azimuthal transmission line to the cathode plate. (b) The width of the high voltage electrode is constant along the upper half circle and gradually decreases on the lower half circle. The pulsed power transmitting from the azimuthal transmission line to cathode plate is also along with the lower half circle. (c) There are two discrete azimuthal transmission lines. The current transmits from the first line to the second line along \pm 80 to \pm 100 degrees. The second line is connected to the cathode plate at four locations extending from \pm 40 to \pm 50 degrees and from \pm 130 to \pm 140 degrees.

transmission line was about $10.4 \Omega$ according to Eq. (1). There were two pieces of insulator rings wrapped around by the azimuthal transmission line high voltage electrode. Six magnetic cores were surrounded by the high voltage conductor, and the corresponding edge at this side was about $15.0 \mathrm{~cm}$ away from the central magnetic core. Corners of $15.0 \mathrm{~mm}$ radius were employed for the two edges to avoid too much electric fields enhancement in those areas.

The electric fields distribution on the azimuthal transmission line high voltage electrode is displayed in Fig. 3. It is clearly seen that the electric fields are distorted at the high voltage conductor's edges and much higher than those in the middle part. The maximum electric field is about $430 \mathrm{kV} / \mathrm{cm}$ and the stressed area is about $2000 \mathrm{~cm}^{2}$. According to circuit simulation, the effective pulse duration is estimated to be about $50.0 \mathrm{~ns}$. Thus, the transformer oil breakdown field in

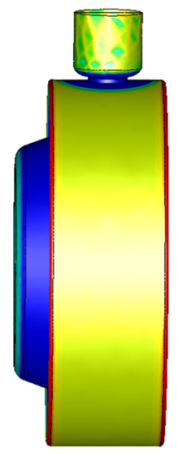

(a)
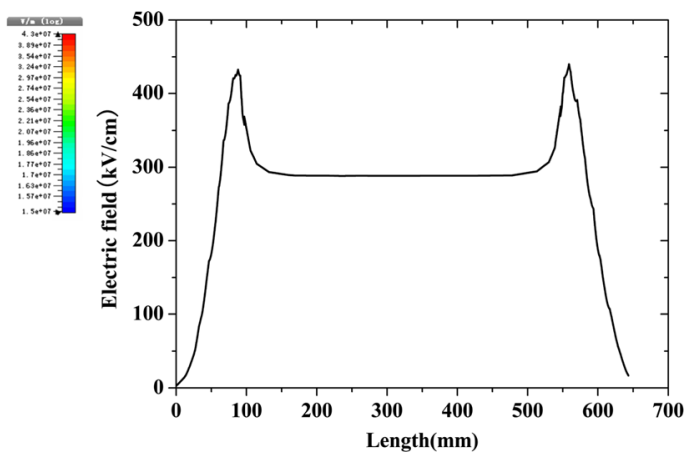

(b)
FIG. 3. Calculated electric fields on the high voltage electrode of the azimuthal transmission line which is the negative electrode; (a) electric fields contour (b) electric stresses in the 90 degrees plane. this area is $1.12 \mathrm{MV} / \mathrm{cm}$ according to Eq. (3). It is found that the maximum electric stress is only $38.3 \%$ of its breakdown field. Figure 4 displays the electric fields distribution on the induction cavity shell. The stressed area is in a limited region which is about $592 \mathrm{~cm}^{2}$, and the transformer oil breakdown field for this electrode is evaluated to be $807 \mathrm{kV} / \mathrm{cm}$ according to Eq. (2).

\section{B. Insulation stack}

The insulation stack in the induction cell is made up of a number of series 45 degree insulator rings separated by

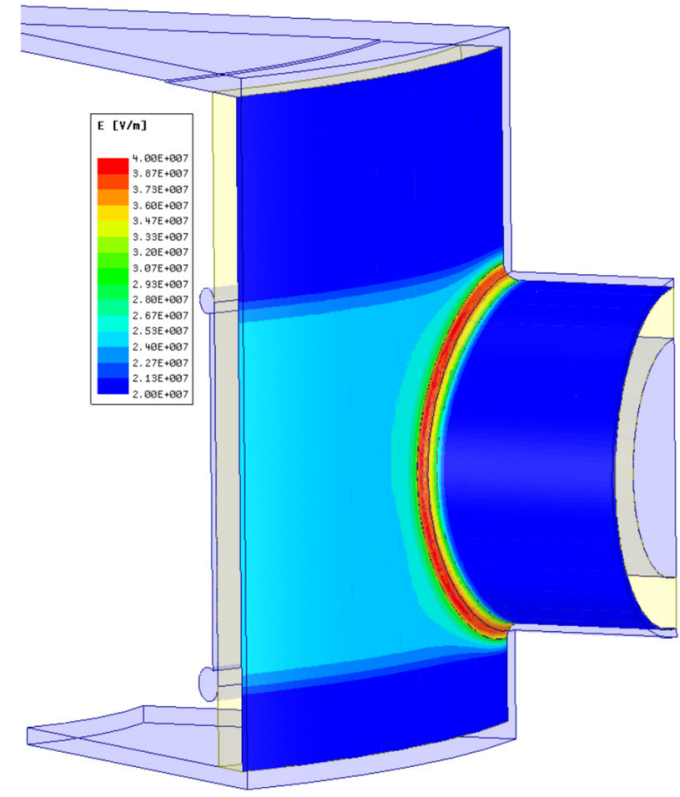

FIG. 4. Plot of electric fields contour on the induction cell shell. The maximum electric field is around the feed port which is about $400.0 \mathrm{kV} / \mathrm{cm}$. 
conducting grading rings. It has also been used successfully in the Z Refurbishment and Primary Test Stand machines. The design criteria are also in common with each other and summarized as follows. The potential grading along each insulator ring should be designed as uniform as possible, and the length of the insulation stack is determined by the Martin equation [24],

$$
E_{b} t^{1 / 6} A^{1 / 10}=175,
$$

where $E_{b}$ refers to the breakdown field normal to the electrodes at which the insulation stack has a 50\% probability of breakdown in $\mathrm{kV} / \mathrm{cm}, t$ is the effective pulse duration defined as the time during which the voltage is above $89 \%$ of the peak value in $\mu s$, and $A$ refers to the insulator rings surface area in $\mathrm{cm}^{2}$. It should be mentioned that the above equation is originally proposed to estimate the flashover of an individual stage. The prediction becomes complicated if there are many insulator rings in the insulation stack. It results from the fact that the effective pulse duration is usually comparable to the transit time of the voltage pulse around the insulation stack perimeter. Flashover initiation at one or more insulator rings is acceptable and will not result in failure of transmitting pulsed power [25].

The maximum electric field on the grading ring should be designed below $300 \mathrm{kV} / \mathrm{cm}$ at the vacuum side and less than $250 \mathrm{kV} / \mathrm{cm}$ at the oil side. The electric field component tangent to the insulator ring is usually less than $30 \mathrm{kV} / \mathrm{cm}$ at the cathode triple junction where the cathode region, vacuum, and insulator meet [26].

The insulation stack in our induction cell was composed of eight pieces of insulator rings that were sandwiched by hard anodized aluminum grading rings. The total axial length of the insulation stack was $280 \mathrm{~mm}$. Polymethyl methacrylate (PMMA) and cross-linked polystyrene (Rexolite) are two kinds of ordinary insulator materials. Rexolite is regarded as a better choice due to its superior flashover resistance, low water absorption, and perfect dimensional stability $[27,28]$. However, the insulator rings made of PMMA were employed during our induction cavity, since PMMA was much cheaper than Rexolite. Hard anodizing was applied to the aluminum grading rings surfaces in order to suppress the electron emission. Anodizing is a process of creating a very hard ceramictype coating on the aluminum and its alloy surface. The thickness of the film formed by the hard anodizing process is higher than $25.0 \mu \mathrm{m}[29,30]$. The electric field on the electrode surface will be reduced by a factor of $\varepsilon_{r}$ by this dielectric layer, where $\varepsilon_{r}$ is the relative permittivity of the coating film. In addition, the coating layer can absorb and shield electrons emitted from the cathode conductor or attenuate the intensity [31].

Table I shows the voltage grading variations from the balanced distribution for each piece of insulator ring which are all less than $10 \%$. The tangential electric fields at the
TABLE I. Potential grading variations from the uniform distribution and the electric fields tangent to the insulator rings at the cathode triple junctions for each insulator ring.

\begin{tabular}{lcc}
\hline \hline Insulator ring & Variation $(\%)$ & $E_{\text {tangent }}(\mathrm{kV} / \mathrm{cm})$ \\
\hline $1 \#$ & $-9.8 \%$ & 14.3 \\
$2 \#$ & $-4.3 \%$ & 15.1 \\
$3 \#$ & $-0.4 \%$ & 14.8 \\
$4 \#$ & $3.9 \%$ & 13.8 \\
$5 \#$ & $7.9 \%$ & 15.7 \\
$6 \#$ & $8.7 \%$ & 15.0 \\
$7 \#$ & $2.9 \%$ & 15.0 \\
$8 \#$ & $-8.8 \%$ & 16.6 \\
\hline \hline
\end{tabular}

cathode triple junctions are also presented in Table I. The maximum value is about $16.6 \mathrm{kV} / \mathrm{cm}$. Table II presents the electric stresses on the metal grading rings which are all below the acceptable level. The insulation stack is a relatively conservative element. It is designed intentionally to reduce the frequency of cleaning, as it will be unavoidably contaminated by the debris from the diode in IVA.

\section{Magnetic core}

The magnetic core usually takes up the largest area in the induction cell to avoid saturation during the interested pulse duration. The condition is expressed as

$$
\Delta B \cdot S=\left(B_{s}+B_{r}\right) S \geq \int_{0}^{T} V(t) d t,
$$

where $\Delta B$ refers to the flux swing that the core material could undergo without saturation, $S$ represents the cross sectional area of the magnetic core, $B_{s}$ and $B_{r}$ correspond to the saturation induction and remanent induction of the material, respectively, and $\int_{0}^{T} V(t) d t$ indicates the integration of the voltage pulse induced across the magnetic core during the interested pulse duration of $T$.

As iron-based amorphous alloy has high saturation induction, which is about 1.6-1.8 $\mathrm{T}$, and relatively low energy loss under high magnetization rate, it is regarded as a preferred magnetic core material in the induction cell

TABLE II. Maximum electric fields normal to the metal grading rings at the vacuum and oil sides.

\begin{tabular}{lcc}
\hline \hline Grading ring & $E_{\text {vacuum }}(\mathrm{kV} / \mathrm{cm})$ & $E_{\text {oil }}(\mathrm{kV} / \mathrm{cm})$ \\
\hline $1 \#$ & 118 & 99 \\
$2 \#$ & 140 & 109 \\
$3 \#$ & 157 & 120 \\
$4 \#$ & 166 & 130 \\
$5 \#$ & 164 & 128 \\
$6 \#$ & 140 & 115 \\
$7 \#$ & 111 & 99 \\
\hline \hline
\end{tabular}


[32-34]. The energy loss in the amorphous alloy under high magnetization rate is dominantly decided by the eddy current induced in the material. In order to suppress the eddy current, amorphous alloy ribbons, thickness of which is about $25 \mu \mathrm{m}$, are commonly used. Each magnetic core comprises thousands of turns of such ribbons, and every lamination is isolated from others. $\mathrm{MgO}, \mathrm{SiO}$, and $\mathrm{SiO}_{2}$ films deposited on the ribbon surface by coating technology and insulation films such as Mylar, Mica paper, and capacitor tissue paper wound between the thin ribbons are the two ordinary processes to provide the insulation material between the laminar ribbons. However, a continuous insulation film could not be obtained with the coating process and its film is usually not able to withstand the induced voltage for per turn in the cell [35]. The voltage hold-off requirement for the insulation film can be calculated as

$$
V=w \delta \frac{d B}{d t},
$$

where $V$ refers to the voltage induced by each lamination, $w$ and $\delta$ denote the ribbon width and thickness, respectively, and $\mathrm{d} B / \mathrm{d} t$ indicates the magnetization rate. Typical width and thickness of the amorphous alloy ribbons are $5.0 \mathrm{~cm}$ and $25 \mu \mathrm{m}$. A voltage approximate $37.5 \mathrm{~V}$ appears between each lamination with a change in induction of $3.0 \mathrm{~T}$ in 100 ns. Moreover, the magnetization rate is always not constant during the pulse duration, and the induced voltage is easily doubled. The insulation films such as Mylar of several microns in thickness can withstand such voltage. The magnetic core fabricated by this process is more suitable for the IVA. In fact, almost all the magnetic cores in the induction cells are manufactured by this technology.

Another issue that must be taken into account is rough estimation of the loss current flowing from the cathode plate to the ground. This current is parallel to the load current and also serves as the magnetic core magnetizing current. It is able to be evaluated by the saturation wave model [36],

$$
I_{\mathrm{loss}}=\left(H_{c}+\frac{\delta^{2}}{4 \rho} \frac{\Delta B}{2 B_{s}} \frac{d B}{d t}\right) l
$$

where $I_{\text {loss }}$ represents the loss current, $H_{c}$ refers to the coercive force, $\rho$ denotes the resistivity of the material, $\Delta B$ indicates the operating flux swing of the magnetic core which is different from the maximum available flux swing in Eq. (5), and $l$ is the average perimeter of the magnetic core. The first term on the right hand denotes the energy loss in the magnetic core related to hysteresis effect, and the second term indicates the energy loss due to the generation of eddy current in the alloy ribbons. It should be mentioned that this model is obtained by assuming that the magnetization rate does not change. However, during the pulse duration, the magnetization rate is variable, and the actual loss current should be larger than the result given by the saturation wave model. Accurate determination of the loss current is very difficult. We suggest that the operating flux swing less than $3.0 \mathrm{~T}$ is a better choice. This design criterion is also employed when designing the RITS and Mercury machines [7,37].

The designer must also take the axial electric fields grading at the outmost of the magnetic cores into consideration. As the amorphous alloy is a conductor, there exist capacitances from the azimuthal transmission line high voltage electrode to the outer turns of the cores. These capacitances strongly influence the electric fields distribution external to the magnetic cores. The design objective is to make the electric fields distribution in this area as uniform as possible and adequately low by adjusting the structures of the azimuthal transmission line and magnetic cores. Typically suitable electric fields are $150-250 \mathrm{kV} / \mathrm{cm}$ for $50 \mathrm{~ns}$ pulse [18].

Table III shows three typical kinds of iron-based amorphous alloys [38-40]. 2605Co has the highest saturation induction. Many IVAs such as RITS, Cygnus, Merlin, and Hermes III have selected $2605 \mathrm{Co}$ as the magnetic core material, but it is more expensive than the other two candidates because of the high cost of cobalt element $[7,10,11,41]$. 2605SA1 has been used extensively in the civil power transformers with the characteristic of low manufacturing cost. Moreover, as the energy loss in the amorphous alloy related to the hysteresis effect also plays an important role in the $50-60 \mathrm{~Hz}$ transformer, the smallest coercive force of this material is helpful to decrease the energy loss. However, since the induced anisotropy energy of $2605 \mathrm{SA} 1$ is much smaller than that of $2605 \mathrm{Co}$, the remanent induction of the magnetic core of 2605SA1 is very sensitive to the mechanical stress caused during the magnetic core fabrication process. The stress is due to differential thermal contraction between the amorphous alloy ribbons and insulation films after thermal annealing the ribbons.

Figure 5 shows the DC B-H loops of the magnetic cores of 2605SA1 fabricated with the two different processes. Since the thickness of the $\mathrm{SiO}_{2}$ insulation film formed by the coating process is about several hundred nanometers, the stress applied to the ribbons is small. The remanent

TABLE III. Properties of three kinds of iron-based amorphous alloys. $B_{s}, H_{c}, \rho$, and $K$ represent the saturation induction, coercive force, resistivity, and induced anisotropy energy of the material, respectively.

\begin{tabular}{lccccc}
\hline \hline $\begin{array}{l}\text { Amorphous } \\
\text { alloy }\end{array}$ & Composition & $B_{s}(T)$ & $H_{c}(\mathrm{~A} / \mathrm{m})$ & $\rho(\mu \Omega \mathrm{m})$ & $K\left(\mathrm{~J} / \mathrm{m}^{3}\right)$ \\
\hline 2605Co & Fe-Co-B-Si & 1.8 & 4 & 1.23 & 920 \\
2605SC & Fe-B-Si-C & 1.6 & 3 & 1.35 & 100 \\
2605SA1 & Fe-B-Si & 1.56 & 2 & 1.37 & $\sim 100$ \\
\hline \hline
\end{tabular}




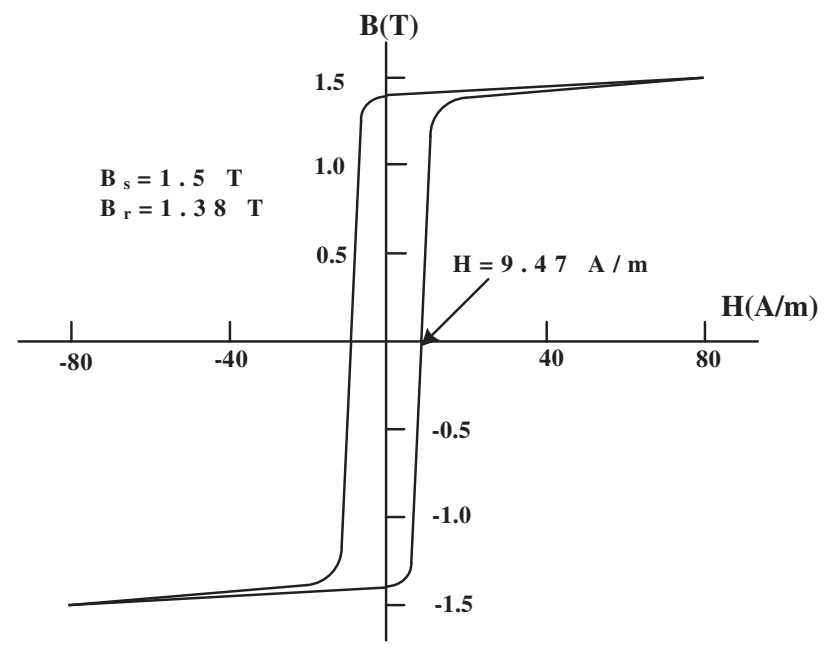

(a)

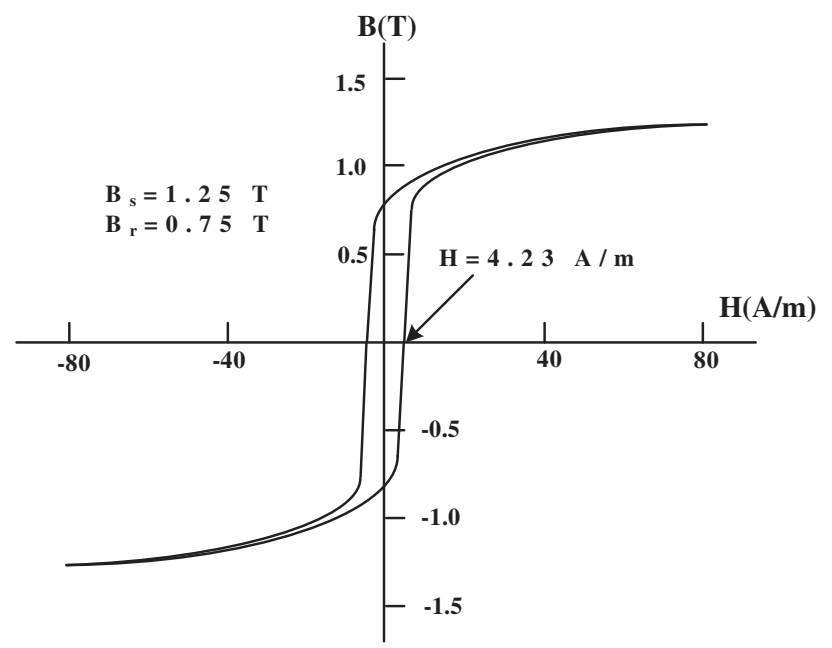

(b)

FIG. 5. DC B-H loops at $80.0 \mathrm{~A} / \mathrm{m}$ of the magnetic cores of $2605 \mathrm{SA} 1$ (a) coated with $\mathrm{SiO}_{2}$ film and (b) co-wound with $10 \mu \mathrm{m}$ capacitor tissue paper. Since the $\mathrm{SiO}_{2}$ film is able to withstand the thermal annealing temperature at about $400{ }^{\circ} \mathrm{C}$, the ribbons are annealed after coating. On the contrary, the capacitor tissue paper cannot withstand the high annealing temperature. The papers are wound with the ribbons after annealing.

induction of the magnetic core is about $1.38 \mathrm{~T}$, and the corresponding squareness ratio of the hysteresis loop $\left(B_{r} / B_{s}\right)$ is 0.92 . The capacitor tissue papers wound between the amorphous alloy ribbons are much thicker. The stress is so strong that the remanent induction decreases to $0.75 \mathrm{~T}$. The squareness ratio of the hysteresis loop is also depressed abruptly. These features behave like the magnetic core of 2605SC material. However, the remanent induction and squareness ratio of the hysteresis loop of the magnetic core of $2605 \mathrm{Co}$ are not significantly degraded by the mechanical stress. The remanent induction as high as $1.6 \mathrm{~T}$ could be achieved with the two fabrication processes [34,35]. Therefore, the volt-second product availability of the magnetic core of $2605 \mathrm{Co}$ will be greater than that of 2605SA1 and 2605SC with the same cross sectional area. 2605Co material is also more suitable for application of magnetic switch, since the high squareness ratio of the hysteresis loop is a desirable characteristic. The magnetic core is employed to increase the impedance of the loss current path in the induction cavity. High squareness ratio is not necessary. The magnetic core of 2605SC or $2605 \mathrm{SA} 1$ is also able to be used. According to the saturation wave model shown in Eq. (7), as the 2605SA1 and 2605Co materials have approximately equal resistivity, the loss current should be almost identical if the operating flux swing of the magnetic core and the induced voltage pulse across the magnetic core are the same.

There were seven magnetic cores in our induction cavity. They were fabricated with $25.0 \mu \mathrm{m}$ 2605SA1 amorphous alloy ribbons and $10.0 \mu \mathrm{m}$ capacitor tissue papers. The packing factor of the magnetic cores was $\sim 0.6$. The width of the amorphous alloy ribbons was $43 \mathrm{~mm}$, and that of capacitor tissue papers was $2.0 \mathrm{~mm}$ wider than the ribbons on each side. The polycarbonate was used to fix the ribbons. The cores build was $21.0 \mathrm{~cm}$, and the core-tocore space that allowed transformer oil flow into the magnetic cores volumes was about $2.5 \mathrm{~mm}$. The saturation and remanent inductions of the seven magnetic cores from DC B-H loops are shown in Table IV. These parameters were also measured with a $20.0 \mathrm{kV}$ pulsed power generator consisting of one $49.0 \mu \mathrm{F}$ capacitor, a self-breaking gas switch, and a water resistor. The capacitor provided the primary energy, and it was switched out by the gas switch. The resistor was employed to protect the capacitor, and the pulse current was unipolar. The polarity of the capacitor charging voltage could be reversed, so the entire B-H loop is also able to be acquired. The magnetizing current of the magnetic core was measured with a Rogowski coil, and the induced voltage pulse across the magnetic core was picked up by one turn loop and detected by a resistor divider. Figure 6 shows the B-H loop of one magnetic core.

TABLE IV. Saturation and remanent inductions of the seven magnetic cores from DC B-H loops at $80.0 \mathrm{~A} / \mathrm{m}$. It should be mentioned that the saturation induction will approach $1.56 \mathrm{~T}$ if the magnetic cores are tested at $800.0 \mathrm{~A} / \mathrm{m}$ condition.

\begin{tabular}{lcc}
\hline \hline Number & $B_{s}(T)$ & $B_{r}(T)$ \\
\hline $1 \#$ & 1.28 & 0.77 \\
$2 \#$ & 1.30 & 0.76 \\
$3 \#$ & 1.28 & 0.70 \\
$4 \#$ & 1.32 & 0.76 \\
$5 \#$ & 1.23 & 0.68 \\
$6 \#$ & 1.28 & 0.74 \\
$7 \#$ & 1.35 & 0.85 \\
\hline \hline
\end{tabular}




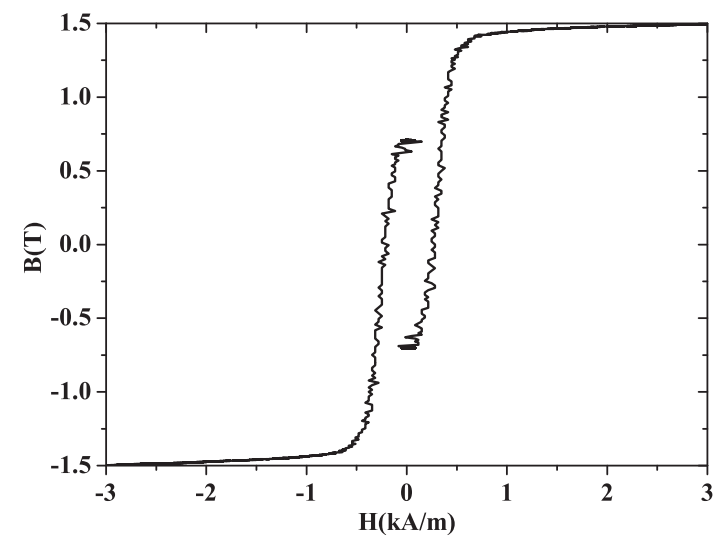

FIG. 6. B-H loop of the No. 2 magnetic core. The breakdown voltage of the gas switch is about $16.2 \mathrm{kV}$. The amplitude of the induced voltage pulse across the magnetic core is $10.4 \mathrm{kV}$, and the pulse duration is $1.4 \mu \mathrm{s}$ before the magnetic core saturates.

The saturation and remanent inductions are about 1.5 and $0.75 \mathrm{~T}$, respectively. The volt-second product availability of this magnetic core is about $12.0 \mathrm{mV}$-second.

As each magnetic core is composed of about 5000 turns of amorphous alloy tapes sandwiched by insulation films, it is impossible to model the metal ribbons and insulation films entirely during the electrostatic simulation model to calculate the axial electric fields outside the magnetic cores. The magnetic core represented by a limited number of conductors and insulation dielectrics with correct proportion and permittivity is also able to estimate the axial electric fields in this area $[18,42]$. Figure 7 shows the calculated axial electric fields at the outmost magnetic cores with and without $1.0 \mathrm{~cm}$ metal bands around the cores outer perimeters. It is clear that the electric fields enhancement at the edges of outer turns could be prevented by the metal bands. They were also employed in the magnetic cores in our induction cell.

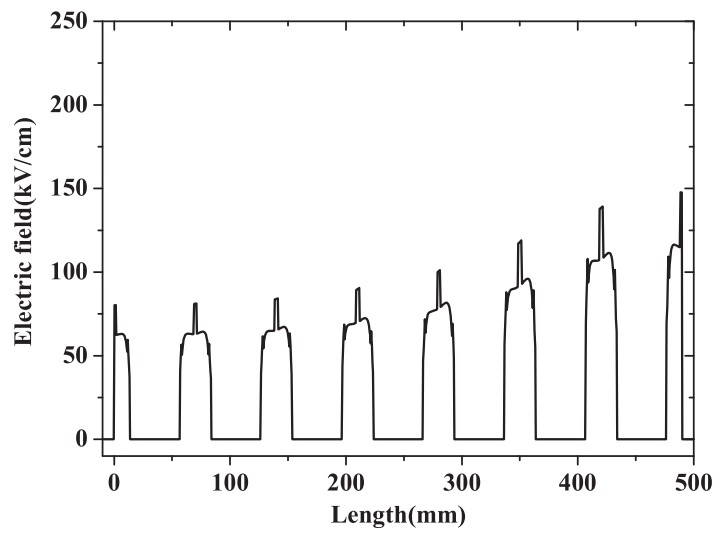

(a)

\section{Cathode plate and output transmission line}

Since the output transmission line in our cell operates as a vacuum insulated transmission line, it is not necessary to estimate the loss current occurring during the MITL. Design of the cathode plate and output transmission line sections is relatively easy. The only design criterion is limiting the electric stresses to about $200 \mathrm{kV} / \mathrm{cm}$. It is also a conservative stress $[10,18]$. The hard anodizing process was also applied to the cathode plate and output transmission line cathode electrode in our cell, and the maximum electric field on the cathode plate surface was $200.0 \mathrm{kV} / \mathrm{cm}$. The radius of the output transmission line anode and cathode electrodes were 236.0 and $330.0 \mathrm{~mm}$, respectively. The characteristic impedance of the output transmission line was about $20.0 \Omega$. Its length was $1.3 \mathrm{~m}$.

\section{EXPERIMENT AND CIRCUIT SIMULATION RESULTS}

During our experiment, the pulse generation section driving the induction cell was identical to the single stage of the future 4.0 MV machine. The tesla transformer was discharged in $3.8 \mu$ s into the intermediate storage capacitor. The capacitance and transit time of the intermediate storage capacitor were $13.5 \mathrm{nF}$ and $54.0 \mathrm{~ns}$, respectively. It was switched out by an LTGS to a $4.0 \Omega, 30.0 \mathrm{~ns}$ PFL which was discharged by a self-breaking oil switch to one $7.0 \Omega$ water transmission line. The transit time of the water transmission line was about 80.0 ns. Figure 8 shows the measured forward-traveling voltage wave in the water transmission line. For this shot, the two capacitors in the pulse transformer were charged to $\pm 60.0 \mathrm{kV}$. A maximum voltage about $1.2 \mathrm{MV}$ could be obtained in the intermediate storage capacitor. The recorded load voltage and current waveforms are shown in Fig. 9. The load voltage waveforms given by the two groups of D-dot monitors agree with each other very well, and the amplitude of the load

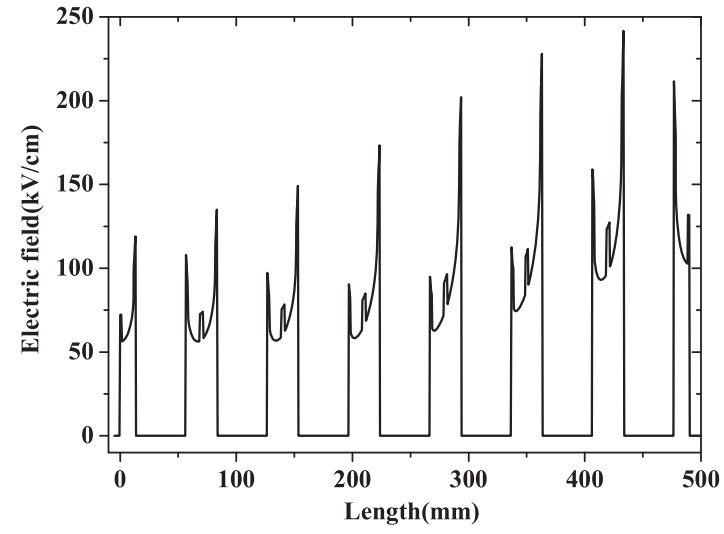

(b)

FIG. 7. Axial electric fields at the outmost of the magnetic cores (a) with metal bands and (b) without metal bands. The maximum electric field is about $150 \mathrm{kV} / \mathrm{cm}$ for the magnetic cores with metal bands, and the corresponding place is close to the azimuthal transmission line high voltage electrode's edge. 


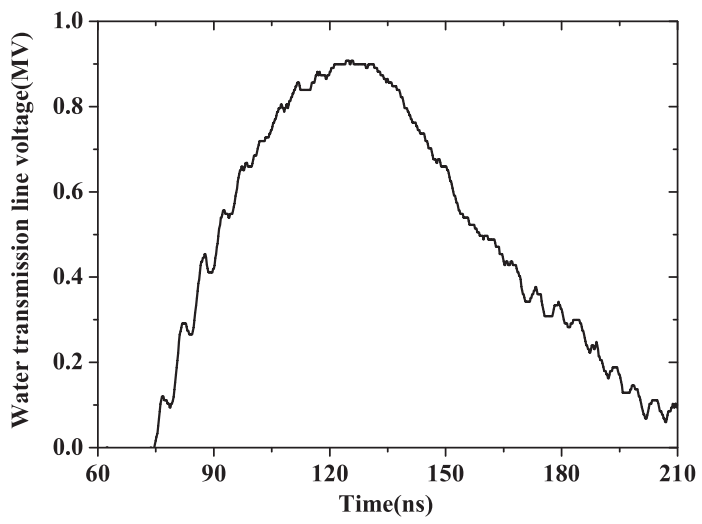

FIG. 8. The forward-going voltage wave traveling in the water transmission line measured by a D-dot monitor placed at the front of the water transmission line. The peak value of the voltage pulse is about $0.9 \mathrm{MV}$.

voltage is about 1.05 MV. The baseline of the load current waveform acquired by the B-dot probes placed on the anode electrode is distorted slightly. This might be due to the fact that the B-dot monitors on the output transmission line inner electrode are at the high voltage potential. The common-mode noise added to the B-dot sensors output signals is higher than that of B-dot monitors on the outer conductor which are at the ground potential. In fact, previous experiments conducted on the negative polarity 1.0 MV-LTD machine also suggested that the performance of the B-dot monitors on the inner electrode was usually not as perfect as those on the outer conductor [43]. However, the amplitudes of the load current given by the two groups of B-dot sensors are also in line with each other very well, and the peak value is about $108.0 \mathrm{kA}$.

A corresponding block diagram of circuit model representation of the single stage of the prospective IVA is shown in Fig. 10. The tesla transformer was modeled by several capacitors, inductors, resistors, and one ideal pulse transformer. The intermediate storage capacitor, PFL, and water transmission line were modeled by one-dimensional (1D) transmission line elements with characteristic impedance and transit time. The feed port of the induction cell was also characterized by one 1D transmission line element. The azimuthal transmission line was divided into 36 mesh cells, the size of which was uniform and 10 degrees around the circumference. Therefore, the azimuthal transmission line was modeled by 36 1D transmission line elements with the same impedance and transit time. However, the insulation stack and cathode plate regions were modeled with 2D transmission line elements. In these sections, the mesh cell size in the azimuthal direction was also uniform and 10 degrees around the circumference and eight nonuniform cells were employed in the radial direction. Each mesh cell possessed one radial element and one azimuthal element modeling the radial and azimuthal directions power flow, respectively. The power flow in the output transmission line region was represented by $1 \mathrm{D}$ transmission line element too. During the circuit simulation model, the shunt resistance of the magnetic cores was evaluated by the following expression $[44,45]$ :

$$
R(t)=\frac{2 S\left(\mu \mu_{0} \rho\right)^{1 / 2}}{\pi^{3 / 2} r_{\text {cores }} \delta t^{1 / 2}} .
$$

The shunt resistance $R(t)$ decreases with the time variable $t$ during the discharge process. $\mu$ and $\mu_{0}$ refer to the relative permeability of the magnetic core material and permeability of free space, respectively. $\mu$ is dependent on the magnetization rate which is not constant during the pulsed power duration. It is in the range of several hundred to one thousand according to previous experiment results [46]. However, it was assumed to be constant and equal to 1000 during our circuit simulation model. $r_{\text {cores }}$ indicates the radius of the centroid of the magnetic cores.

Figure 11 displays the azimuthal transmission line voltage waveforms obtained during the experiment and

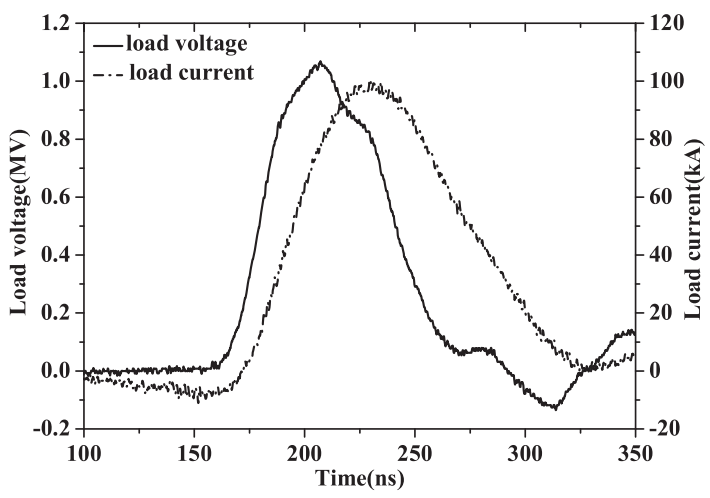

(b)

FIG. 9. The load voltage (black solid line) and load current (black dash-dotted line) waveforms detected by the sensors placed on the output transmission line (a) cathode electrode and (b) inner conductor. All the waveforms are obtained by averaging the output signals of the two sensors placed at the same cross section. The rise time of the load voltage waveform is about $28.5 \mathrm{~ns}$ and the FWHM is $60.0 \mathrm{~ns}$. 


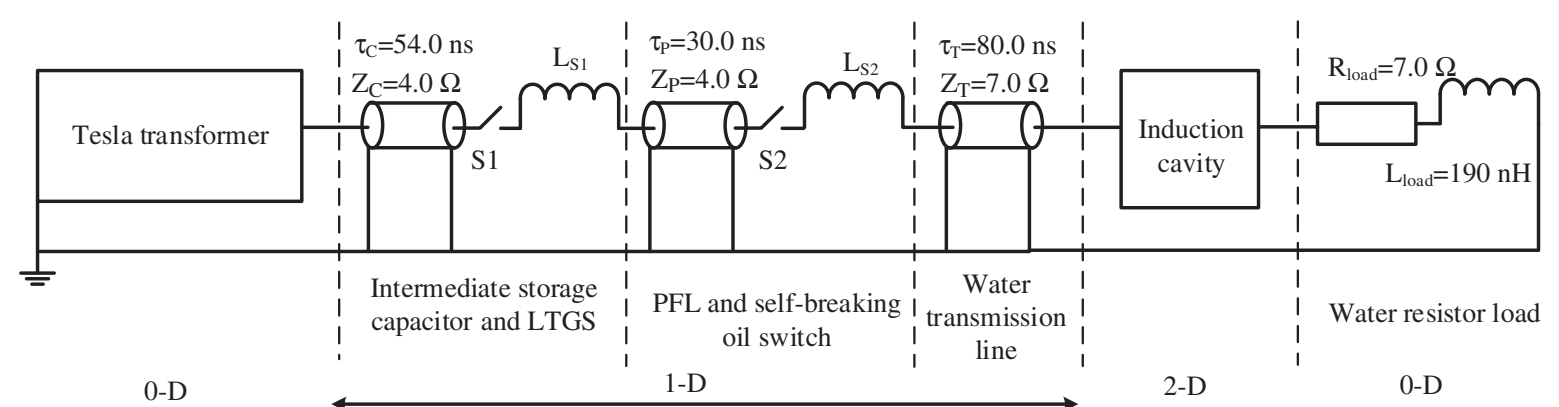

FIG. 10. Block diagram of the circuit model including the tesla transformer, intermediate storage capacitor, LTGS, PFL, self-breaking oil switch, water transmission line, induction cell, and water resistor load. $\tau_{C}$ and $\mathrm{Z}_{C}$ refer to the one-way transit time and impedance of the intermediate storage capacitor, respectively. S1 represents the LTGS and $L_{S 1}$ indicates its inductance. $\tau_{P}$ and $Z_{P}$ are the one-way transit time and impedance of the PFL, respectively. S2 represents the self-breaking oil switch and $L_{S 2}$ indicates its inductance. $\tau_{T}$ and $\mathrm{Z}_{T}$ are the one-way transit time and impedance of the water transmission line, respectively. $R_{\text {load }}$ and $L_{\text {load }}$ denote the resistance and inductance of the water resistor load, respectively.

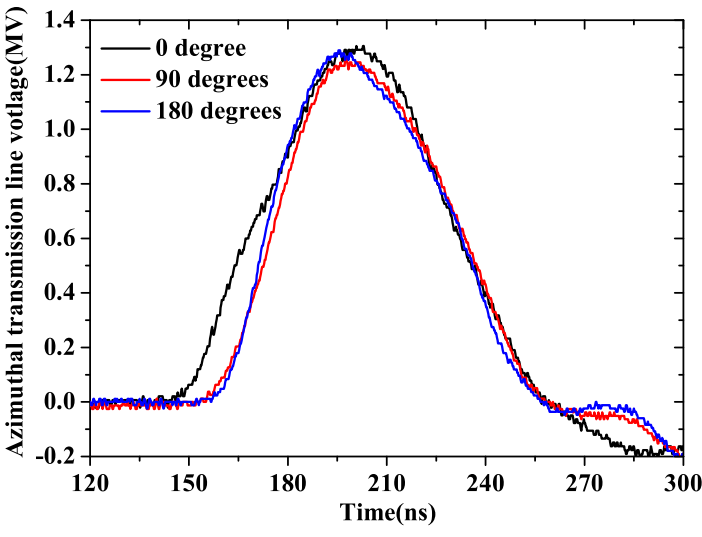

(a)

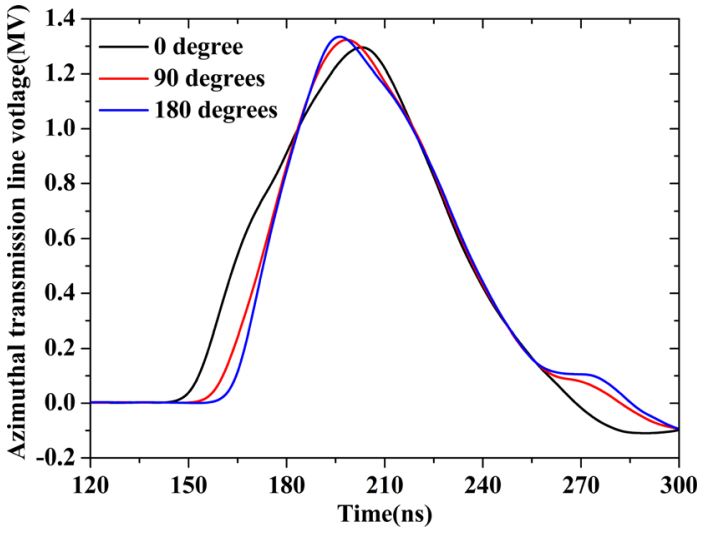

(b)

FIG. 11. The azimuthal transmission line voltage waveforms at 0 degree (black solid line), 90 degrees (red solid line), and 180 degrees (blue solid line) given by (a) experiment and (b) circuit simulation. As the length of feed port of our induction cell was only 257 mm and the D-dot sensor placed at the feed port was very close to the azimuthal transmission line, the voltage waveform given by this D-dot monitor was also able to be treated as azimuthal transmission line voltage at 0 degree. The maximum voltage at the azimuthal transmission line section is about $1.3 \mathrm{MV}$.

by circuit simulation. It is clear that the rise time of the azimuthal transmission line voltage waveform at 0 degree is greater than that of voltage waveforms at 90 and 180 degrees. This is not only observed during the experiment but also predicted by circuit simulation. The effective pulse duration of the measured azimuthal transmission line voltage waveform at 0 degree is $48.2 \mathrm{~ns}$. It is very close to the result given by circuit simulation which is about 49.2 ns. The peak values of the voltage pulses are also in line with each other. Accurate determination of the amplitude and effective pulse duration of the voltage waveform are very crucial to estimate the breakdown electric field at this section. The comparison of the current waveforms at the induction cavity feed port section is shown in Fig. 12. The two curves acquired during the experiment and by circuit simulation also agree with each other, especially at the rising edge. The maximum currents

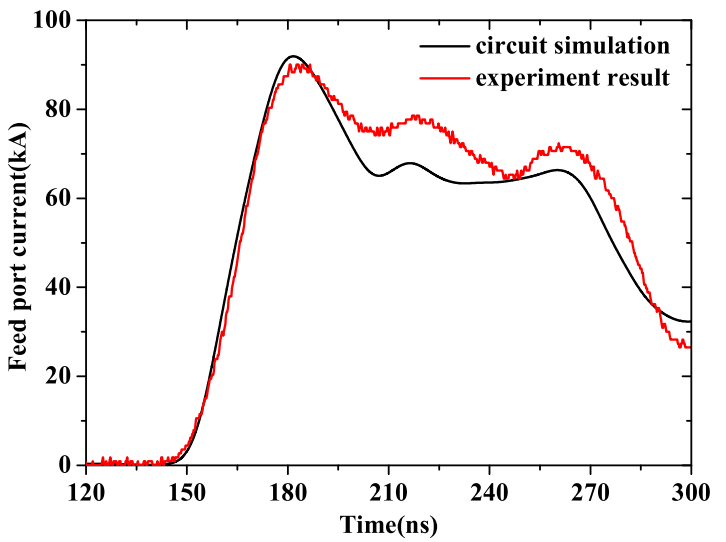

FIG. 12. Comparison of the simulation (black solid line) and measurement result (red solid line) of the current waveforms at the induction cavity feed port section. 


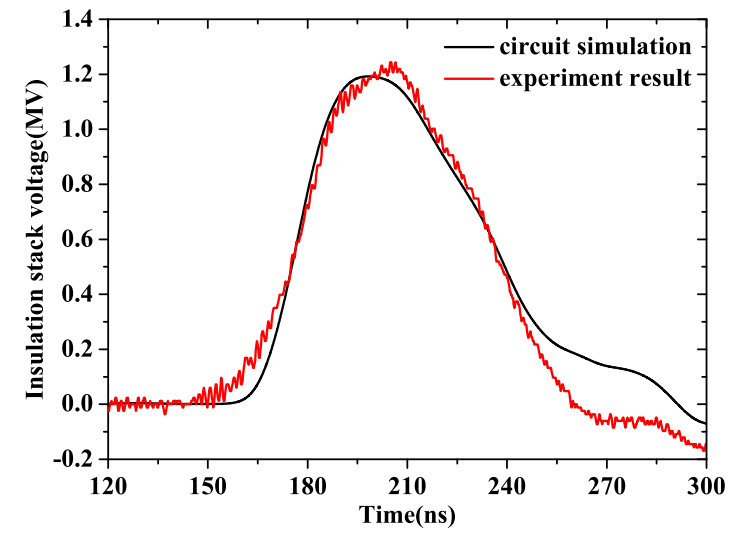

(a)

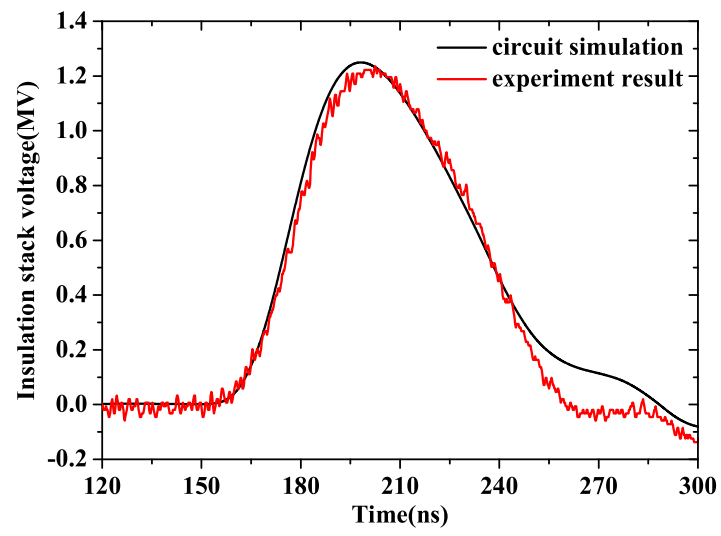

(b)

FIG. 13. Comparison of the simulation (black solid line) and experiment results (red solid line) of the insulation stack voltage waveforms at (a) 30 degrees and (b) 90 degrees. The calculated voltage waveforms are in agreement with the measurement results over most of the pulse duration.

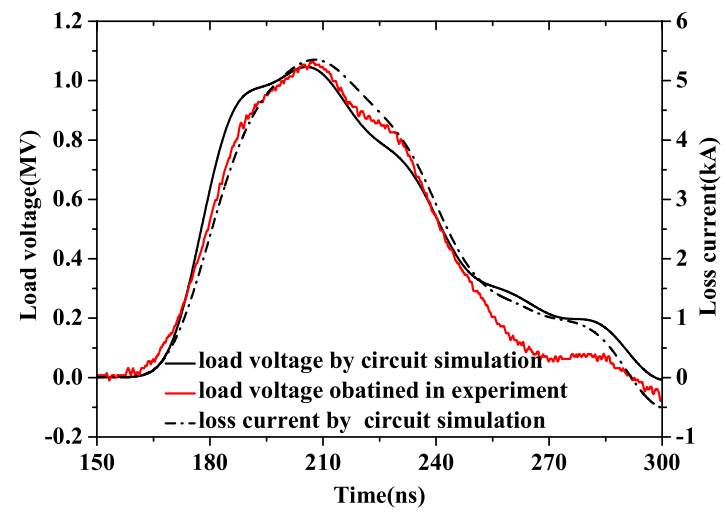

FIG. 14. The load voltage waveforms given by circuit simulation (black solid line) and acquired during the experiment (red solid line). The black dash-dotted line represents the loss current around the magnetic cores obtained by circuit simulation.

are about 89.8 and $91.9 \mathrm{kA}$ in the experiment and calculation, respectively. Figure 13 depicts the comparison of the voltage waveforms at the insulation stack section. The effective pulse durations at this part acquired during the experiment and by circuit calculation are 23.6 and $22.1 \mathrm{~ns}$, respectively, and the maximum voltage is about 1.2 MV. These values decide the breakdown field at the insulation stack section. The load voltage waveforms are exhibited in Fig. 14. The peak value of the load voltage given by circuit simulation is about $1.05 \mathrm{MV}$, which is almost equal to the experiment result. The consistency suggests that the shunt resistance circuit model of the magnetic cores employed in the calculation is approximately reasonable. Figure 14 also displays the loss current around the magnetic cores, and the corresponding maximum value is about $5.2 \mathrm{kA}$. It indicates that the impedance of the loss current path is significantly larger than that of the resistor load.

\section{CONCLUSIONS}

In the presented work, we have shown a full-scale prototype induction cavity as part of the program to develop the future 4.0 MV IVA. The azimuthal transmission line is designed with a constant impedance profile along the entire circumference. The magnetic cores of 2605SA1 are employed instead of conventional 2605Co material. Although the squareness ratio of their hysteresis loops is low, they also show a good performance. A full circuit model indicating one of the six stages of the $4.0 \mathrm{MV}$ machine is proposed, and the power flow in the induction cell is represented by the $2 \mathrm{D}$ circuit model which is able to model the radial and azimuthal directions power flow at the insulation stack and cathode plate regions. The voltage waveforms at the feed port, azimuthal transmission line, and insulation stack sections and the current trace at the feed port section obtained during the experiment are compared with the circuit simulation results, which show satisfactory agreement.

Based on the circuit model of the single stage, a full circuit model denoting the 4.0 MV machine is completed. The circuit simulation results suggest that the maximum voltage across the induction cavity is about $1.0 \mathrm{MV}$ in order to get the desired load voltage if the six cells are fired synchronously with the speed at which the electromagnetic wave propagates along the output transmission line. However, because of the jitters of LTGS and self-breaking oil switch, the induction cavity is usually not able to be driven at the time when the electromagnetic wave arrives at this cell. Anomalous voltages will be produced across the cells [7]. The amplitude of the anomalous cell voltages is determined by the quantity of the induction cavities, the jitters of the switches, and the rise time of the voltage pulse driving the cavity. It is important to consider the relationship between the anomalous voltages and the three factors when finally designing the 4.0 MV machine. The induction 
cavity 2D circuit model will serve as a useful tool to carry out such an investigation. Moreover, in order to avoid electron emission from the negative outer electrode, the output transmission line impedance profile of the prospective 4.0 MV IVA could not be designed with stepped impedance either in driver-matched or load-matched mode like other IVAs. The corresponding impedance of the output transmission line at each induction cavity will be larger than the summed impedance of upstream pulse forming sections. The proposed circuit model is also desirable to design the output transmission line impedance profile of the 4.0 MV machine.

\section{ACKNOWLEDGMENTS}

This work is supported by the Joint Funds of the National Natural Science Foundation of China (Grant No. U1530133).

[1] J. Maenchen, G. Cooperstein, J. O'Malley, and I. Smith, Advances in pulsed power-driven radiography systems, Proc. IEEE 92, 1021 (2004).

[2] T. J. Goldsack, T. F. Bryant, P. F. Beech, S. G. Clough, G. M. Cooper, R. Davitt, R. D. Edwards, N. Kenna, J. McLean, A. G. Pearce, M. J. Phillips, K. P. Pullinger, D. J. Short, M. A. Sinclair, K. J. Thomas, J. R. Threadgold, M. C. Williamson, and K. Krushelnick, Multimegavolt multiaxis high-resolution flash x-ray source development for a new hydrodynamics research facility at AWE Aldermaston, IEEE Trans. Plasma Sci. 30, 239 (2002).

[3] J. C. Zier, D. Mosher, R. J. Allen, R. J. Commisso, G. Cooperstein, D. D. Hinshelwood, S. L. Jackson, D. P. Murphy, P. F. Ottinger, A. S. Richardson, J. W. Schumer, S. B. Swanekamp, and B. V. Weber, High-power, photofission-inducing bremsstrahlung source for intense pulsed active detection of fissile material, Phys. Rev. ST Accel. Beams 17, 060401 (2014).

[4] J. A. Halbleib, T. W. L. Sanford, and J. W. Poukey, Radiation environment of Hermes III, IEEE Trans. Nucl. Sci. 35, 1282 (1988).

[5] K. Z. Zhang, L. Wen, H. Li, Z. Y. Dai, W. D. Wang, W. W. Zhang, M. Wang, J. Li, A. M. Yang, Y. T. Xie, S. F. Chen, H. C. Wang, G. S. Dai, J. S. Shi, L. W. Zhang, J. J. Deng, and B. N. Ding, Dragon-I injector based on the induction voltage adder technique, Phys. Rev. ST Accel. Beams 9, 080401 (2006).

[6] J. J. Ramirez, K. R. Prestwich, E. L. Burgess, J. P. Furaus, R. A. Hamil, D. L. Johnson, T. W. L. Sanford, L. O. Seamons, L. X. Schneider, and G. A. Zawadzkas, The Hermes-III program, in Proceedings of the 6th IEEE International Pulsed Power Conference, edited by P. J. Turchi and B. H. Bernstein (IEEE, Arlington, VA, 1987), p. 294.

[7] I. D. Smith, V. L. Bailey, Jr., J. Fockler, J. S. Gustwiller, D. L. Johnson, J. E. Maenchen, and D. W. Droemer, Design of a radiographic integrated test stand (RITS) based on a voltage adder, to drive a diode immersed in a high magnetic field, IEEE Trans. Plasma Sci. 28, 1653 (2000).

[8] N. Bruner, T. Genoni, E. Madrid, D. Rose, D. Welch, K. Hahn, J. Leckbee, S. Portillo, B. Oliver, V. Bailey, and D. Johnson, Modeling particle emission and power flow in pulsed-power driven, nonuniform transmission lines, Phys. Rev. ST Accel. Beams 11, 040401 (2008).

[9] N. Bruner, T. Genoni, E. Madrid, D. Welch, K. Hahn, and B. Oliver, Excitation of voltage oscillations in an induction voltage adder, Phys. Rev. ST Accel. Beams 12, 070401 (2009).

[10] D. Weidenheimer, P. Corcoran, R. Altes, J. Douglas, H. Nishimoto, I. Smith, R. Stevens, D. L. Johnson, R. White, J. Gustwiller, J. E. Maenchen, P. Menge, R. Carlson, R. D. Fulton, G. Cooperstein, D. Droemer, and E. Hunt, Design of a driver for the Cygnus X-ray source, in Proceedings of the 13th IEEE International Pulsed Power Conference, edited by B. Reinovsky and M. Newton (IEEE, Las Vegas, NV, 2001), p. 591.

[11] K. Thomas et al., The MERLIN induction voltage adder radiographic accelerator, in Proceedings of the 21th IEEE International Pulsed Power Conference (IEEE, Brighton, UK, 2017), p. 1.

[12] H. Wei, F. J. Sun, T. X. Liang, J. M. Guo, A. C. Qiu, P. T. Cong, J. H. Yin, Y. X. Hu, X. F. Jiang, Z. G. Wang, and T. F. Dang, Experimental study and electromagnetic model of a 1-MV induction voltage cavity, IEEE Trans. Plasma Sci. 43, 3359 (2015).

[13] I. Smith, P. Corcoran, V. Carboni, V. Bailey, H. Kishi, D. L. Johnson, J. Maenchen, I. Molina, R. Carlson, D. Fulton, K. Hahn, J. Smith, D. Droemer, K. Thomas, M. Phillips, S. Croxon, R. Forgan, and I. D. Smith, Induction voltage adder architectures, and electrical characteristics, in Proceedings of the 14th IEEE International Pulsed Power Conference, edited by M. Giesselmann and A. Neuber (IEEE, Dallas, TX, 2003), p. 371.

[14] J. J. Ramirez, K. R. Prestwich, and I. D. Smith, Highpower, short-pulse generators based on induction voltage adders, Proc. IEEE 80, 946 (1992).

[15] F. Guo, W. K. Zou, B. Y. Gong, J. H. Jiang, L. Chen, M. Wang, and W.P. Xie, Modeling power flow in the induction cavity with a two dimensional circuit simulation, Phys. Rev. Accel. Beams 20, 020401 (2017).

[16] H. Wei, F. J. Sun, T. X. Liang, J. H. Yin, T. F. Dang, J. T. Zeng, P. T. Cong, and A.C. Qiu, Low voltage pulse injection test of a single-stage $1 \mathrm{MV}$ prototype induction voltage adder cell, Rev. Sci. Instrum. 85, 083506 (2014).

[17] B. V. Oliver, T. C. Genoni, D. L. Johnson, V. L. Bailey, P. Corcoran, I. Smith, J. E. Maenchen, I. Molina, and K. Hahn, Two and three-dimensional MITL power-flow studies on RITS, in Proceedings of the 14th IEEE International Pulsed Power Conference (Ref. [13]) (IEEE, Dallas, TX, 2003), p. 395.

[18] I. D. Smith, Induction voltage adders and the induction accelerator family, Phys. Rev. ST Accel. Beams 7, 064801 (2004).

[19] A. F. Peterson and G. D. Durgin, Transient Signals on Transmission Lines: An Introduction to Non-Ideal Effects and Signal Integrity Issues in Electrical Systems (Morgan \& Claypool Publishers, Arizona, 2009). 
[20] A. Jones, Calculation of voltage available from polarity reversal of a superswarf X-ray machine, in Proceedings of the 19th IEEE International Pulsed Power Conference, edited by B. V. Oliver, J. P. Verboncoeur, and M. T. Crawford (IEEE, San Francisco, CA, 2013), p. 1272.

[21] J. J. Leckbee, S. R. Cordova, M. D. Johnston, B. V. Oliver, T. J. Webb, D. R. Ziska, V. L. Bailey, P. A. Corcoran, I. D. Smith, and B. A. Whitney, Positive-polarity rod-pinch experiments on the RITS-6 accelerator, in Proceedings of the 19th IEEE International Pulsed Power Conference (Ref. [20]) (IEEE, San Francisco, CA, 2013), p. 492.

[22] H. Wei, F. J. Sun, A. C. Qiu, J. T. Zeng, J. H. Yin, T. X. Liang, and Y.X. Hu, Optimized design of azimuthal transmission lines for the cell driven by two PFLs in induction voltage adders, IEEE Trans. Plasma Sci. 41, 2421 (2013).

[23] F. Guo, Z. Wang, J. H. Jiang, W. K. Zou, B. Y. Gong, L. Chen, and W. P. Xie (unpublished).

[24] I. D. Smith, P. A. Corcoran, W. A. Stygar, T. H. Martin, R. B. Spielman, and R. W. Shoup, Design criteria for the Z vacuum insulator stack, in Proceedings of the 11th IEEE International Pulsed Power Conference, edited by G. Cooperstein and I. Vitkovitsky (IEEE, Baltimore, MA, 1997), p. 168.

[25] I. Smith, Flashover of vacuum interfaces with many stages, and large transit times, in Proceedings of the 10th IEEE International Pulsed Power Conference, edited by W. Baker and G. Cooperstein (IEEE, Albuquerque, NM, 1995), p. 558.

[26] R. W. Shoup, F. Long, T. H. Martin, R. B. Spielman, W. A. Stygar, M. A. Mostrom, K. W. Struve, H. Ives, P. Corcoran, and I. Smith, Design validation of the PBFA-Z vacuum insulator stack, in Proceedings of the 11th IEEE International Pulsed Power Conference (Ref. [24]) (IEEE, Baltimore, MA, 1997), p. 1608.

[27] H. C. Ives, D. M. Van De Valde, F. W. Long, J. W. Smith, R. B. Spielman, W. A. Stygar, R. W. Wavrik, and R. W. Shoup, Engineering design of the $\mathrm{Z}$ magnetically-insulated transmission lines, and insulator stack, in Proceedings of the 11th IEEE International Pulsed Power Conference (Ref. [24]) (IEEE, Baltimore, MA, 1997), p. 1602.

[28] W. A. Stygar et al., Improved design of a high-voltage vacuum-insulator interface, Phys. Rev. ST Accel. Beams 8, 050401 (2005).

[29] P. Flores, D. J. Henderson, D. E. Good, K. Hogge, C. V. Mitton, I. Molina, C. Naffziger, S. R. Codova, and E. C. Ormond, Anodizing of high electrically stressed components, in Proceedings of the 19th IEEE International Pulsed Power Conference (Ref. [20]) (IEEE, San Francisco, CA, 2013), p. 891.

[30] Z.F. Zhu, Technology of Anodic Oxidation and Surface Treatment on Aluminum Alloys, 2nd ed. (Chemical Industry Press, Beijing, 2009) (in Chinese).

[31] Y. Gao, A. C. Qiu, Z. Zhang, P. F. Zhang, Z. G. Wang, and H. L. Yang, Research on pinching characteristics of electron beams emitted from different cathode surfaces of a rod-pinch diode, Phys. Plasmas 17, 073108 (2010).
[32] C. H. Smith, Magnetic pulse compression by metallic glasses, J. Appl. Phys. 64, 6032 (1988).

[33] C. H. Smith, Applications of amorphous magnetic materials at very-high magnetization rates, J. Appl. Phys. 67, 5556 (1990).

[34] G. E. Fish, Soft magnetic materials, Proc. IEEE 78, 947 (1990).

[35] C. H. Smith, B. N. Turman, and H. C. Harjes, Insulations for metallic glasses in pulse power systems, IEEE Trans. Electron Devices 38, 750 (1991).

[36] A. A. Kim, M. G. Mazarakis, V. I. Manylov, V. A. Vizir, and W. A. Stygar, Energy loss due to eddy current in linear transformer driver cores, Phys. Rev. ST Accel. Beams 13, 070401 (2010).

[37] J. Fockler, K. Nielsen, H. Nishimoto, I. Smith, W. Bauer, K. Baumung, H. Bluhm, P. Hoppe, H. U. Karow, G. Kessler, W. Ratajczak, and D. Rusch, Design of a $6 \mathrm{MV}, 2$ TW positive ion driver using an induction adder, in Proceedings of the 9th IEEE International Pulsed Power Conference, edited by K. Prestwich and W. Baker (IEEE, Albuquerque, NM, 1993), p. 431.

[38] C. H. Smith and L. Barberi, Dynamic magnetization of metallic glasses, in Proceedings of the 5th IEEE International Pulsed Power Conference, edited by M. F. Rose and P. J. Turchi (IEEE, Arlington, VA, 1985), p. 664.

[39] C. H. Smith, Magnetic losses in metallic glasses under pulsed excitation, IEEE Trans. Nucl. Sci. 30, 2918 (1983).

[40] A. W. Molvik and A. Faltens, Induction core alloys for heavy-ion inertial fusion-energy accelerators, Phys. Rev. ST Accel. Beams 5, 080401 (2002).

[41] C. W. Huddle, D. L. Johnson, G. J. Denison, and T. L. Franklin, Testing of the inductive cores for Hermes III, in Proceedings of the 6th IEEE International Pulsed Power Conference (Ref. [6]) (IEEE, Arlington, VA, 1987), p. 494.

[42] I. D. Smith, Lee Schlitt's contributions to pulsed power, in Proceedings of the 15th IEEE International Pulsed Power Conference, edited by J. Maenchen and E. Schamiloglu (IEEE, Monterey, CA, 2005), p. 16.

[43] F. Guo, W. K. Zou, L. Q. Liu, L. Chen, B. Wei, D. G. Liu, M. Wang, and W. P. Xie, Current transmission efficiency for conical magnetically insulated transmission line on a 1.0-MV linear transformer driver system, IEEE Trans. Plasma Sci. 43, 2663 (2015).

[44] W. A. Stygar et al., Conceptual designs of two petawattclass pulsed-power accelerators for high-energy-densityphysics experiments, Phys. Rev. ST Accel. Beams 18, 110401 (2015).

[45] D. V. Rose, C. L. Miller, D. R. Welch, R. E. Clark, E. A. Madrid, C. B. Mostrom, W. A. Stygar, K. R. LeChien, M. A. Mazarakis, W. L. Langston, J. L. Porter, and J. R. Woodworth, Circuit models and three-dimensional electromagnetic simulations of a 1-MA linear transformer driver stage, Phys. Rev. ST Accel. Beams 13, 090401 (2010).

[46] R. Burdt and R. D. Curry, Magnetic core test stand for energy loss and permeability measurements at a high constant magnetization rate and test results for nanocrystalline and ferrite materials, Rev. Sci. Instrum. 79, 094703 (2008). 